\title{
Role of White blood Cell Count and Mean Platelet Volume ratio in Acute Coronary Syndrome patients: A short study
}

\author{
S. Rama Devi ${ }^{1}$ \\ ${ }^{1}$ Dept. Laboratory, Aster Prime Hospital, Hyderabad, India629899
}

\begin{abstract}
Address for correspondence Dr. S. Rama Devi, MBBS, MD, MBA, Consultant Pathologist, Dept. Laboratory, Aster Prime Hospital, Hyderabad, India (e-mail: drseerararamadevi@gmail.com).
\end{abstract}
Abstract
The white blood cell count to mean platelet volume ratio is an indicator of Keywords
- ACS
- WMR inflammation in patients with atherosclerotic disease. Acute coronary syndrome is a disease characterized in most of the cases by rupture of atherosclerotic plaque and subsequent complete or incomplete thrombosis of the coronary arteries.
- MACE
- TAT

\section{Introduction}

That white blood cells (WBC) count to mean platelet volume (MPV) ratio (WMR) is an inflammatory marker in atherosclerotic diseased patients is already established. The characteristic feature of acute coronary syndrome (ACS) is rupture of atherosclerotic plaque, which is seen in in an increasing number of cases either by complete or incomplete occlusion of coronary arteries via thrombus formation. ${ }^{1}$

The potential role of leukocytes is proven in cardiovascular events. After an endothelial injury, T-cell and macrophage are activated, which are present in atherosclerotic plaque which, in turn, leads to the production of procoagulants and cytokines, thereby leading to the formation of thrombus. ${ }^{2}$

Also, there are studies which have suggested that platelets (both activated and inactivated forms) have a role to play in inflammatory pathways of acute coronary events by the production of adhesion molecules and cytokines, leading to atherogenesis.

At the site of plaque rupture, there is an enhancement of leucocytes due to interaction between platelets and leukocytes.
All these events and processes are important in elevating ACS development and its prognosis

It has been reported that the associated factors of cardiovascular morbidity and mortality are leukocyte differentials and platelet activation markers and; comorbidities such as hypertension, diabetes mellitus, obesity, and hypercholesterolemia are also associated with them.

This marker is cost-effective and easily available in complete blood picture; moreover, turnaround time (TAT) is less.

At the time of admission in patients with ACS, elevated WMR has more risk in multivessel disease and mortality when compared to lower WMR, therefore major adverse cardiac events (MACE) and worse outcomes can be predicted. ${ }^{3,4}$

It has been reported that high risk is seen in young women with ACS. ${ }^{5}$

An article titled, "Usefulness of WBC count to Mean platelet volume ratio in predicting short term (30 days) major adverse cardiac events in patients presenting with Acute Coronary Syndrome and its comparison in males and females" published in this journal has relevance and is significant, as only a few studies have been done as per literature.
DOI https://doi.org/ 10.1055/s-0041-1732505 (c) 2021. Women in Cardiology and Related Sciences.

This is an open access article published by Thieme under the terms of the Creative Commons Attribution-NonDerivative-NonCommercial-License, permitting copying and reproduction so long as the original work is given appropriate credit. Contents may not be used for commercial purposes, or adapted, remixed, transformed or built upon. (https://creativecommons.org/licenses/by-nc-nd/4.0/).

Thieme Medical and Scientific Publishers Pvt. Ltd. A-12, 2nd Floor, Sector 2, Noida-201301 UP, India 
In this current study, the best part was gender comparison; besides, other factors such as noninvasiveness, being easily accessible for interpretation, and short TAT are helpful for early diagnosis and management of MACE events and ACS.

This study involves a wide range of investigations done like CPK, LDH, AST, ALT, ALP, bilirubin, urea, creatinine, and lipid profile, but its importance/effect on short-term MACE was not explained in detail, and interdependence with WMR was also not established.

The key article was not relevant; also, sample size and duration of the study were less. Equipment and diagnostic criteria like Wilson score references (article) and regional variations in other countries were not described in the study.

Overall, even though it is statistically significant, further research in large study subjects is required in India to understand the role and importance of WMR, which helps ACS patients in predicting MACE and its treatment, a game changer in life-saving measures.

\section{Conflict of Interest}

None declared.

\section{References}

1 Emre AR, Yasar KA, Atakan Y, Orhan C, Murathan K. Relationship between White blood cell count and mean platelet volume Ratio and clinical outcomes and severity of coronary artery disease in patients undergoing primary percutaneous coronary intervention. Cardiovasc Ther 2020;2020:9625181

2 Adam AM, Rizvi AH, Haq A, et al. Prognostic value of blood count parameters in patients with acute coronary syndrome. Indian Heart J 2018;70(2):233-240

3 Sivri S, Sokmen E, Celik M, Ozbek SC, Yildirim A, Boduroglu Y. Usefulness of white blood cell count to mean platelet volume ratio in the prediction of SYNTAX score in patients with non-ST elevation myocardial infarction. Pak J Med Sci 2019;35(3):824-829

4 Shanker S, Reddy S, Ramachandran G. Usefulness of white blood cell count to mean platelet volume ratio in predicting short term, 30 days major adverse cardiac events in patients presenting with acute coronary syndrome. International J Res Med Sci 2020;8(4):1404-1413

5 Davis M, Diamond J, Montogomery D, Krishnan S, Eagle K, Jackson E. Acute coronary syndrome in young women under 55 years of age: clinical characteristics, treatment, and outcomes. Clin Res Cardiol 2015;104(8):648-55 